\title{
Lower uterine segment involvement in lymphovascular space invasion and lymph node metastasis in endometrioid endometrial cancer
}

\author{
Hakan Cokmez, Alpay Yilmaz \\ Department of Obstetrics and Gynecology, Izmir Ataturk Education and Research Hospital, Karabaglar, Izmir, Turkey
}

\begin{abstract}
Objectives: To evaluate the correlation between lymphovascular space invasion (LVSI) indicating lower uterine segment involvement (LUSI) in endometrioid endometrial cancer and lymph node metastasis based on the lymphatic drainage difference between the uterine corpus and the lower segment.

Material and methods: Patients who underwent staging surgery for endometrioid endometrial cancer between January 2010 and January 2019 at our institution were reviewed. The clinicopathologic findings and LUSI status of the patients were compared with their LVSI and lymph node metastasis status.

Results: Of the 253 patients included in this study, 49 (19.4\%) had LUSI. Among these patients, none of the 31 LVSI-negative patients had metastatic lymph node involvement. However, of the 18 LVSI-positive patients, half had metastatic lymph node involvement; this difference was significant $(p<0.05)$.

Conclusions: The significant correlation between LVSI and lymph node metastasis in LUSI-positive cases indicates that pathologists should also focus on LVSI findings in the frozen examination required for the decision of staging surgery in patients with endometrioid endometrial cancer limited to the uterus. This is especially important in patients with a lower uterine segment involvement.
\end{abstract}

Key words: endometrial cancer; lower uterine segment; lymphovascular space invasion; lymph node metastasis

Ginekologia Polska 2019; 90, 6: 314-319

\section{INTRODUCTION}

Although endometrial cancer ranks eighth among the most common 15 cancers in women in terms of incidence, it ranks 13 th for mortality. This is because, in developing countries, these cases are usually diagnosed at an early stage; thus, the survival rates are high following primary surgery [1]. However, there are studies showing that lymphovascular space invasion (LVSI), defined as tumour cell accumulation in the lymphatic and blood vessels close to the invasive margin [2], is an independent risk factor for lymph node metastasis, even in these early stage endometrial cancer cases [3-6]. Nevertheless, unlike myometrial invasion and histological grade, which indicate the risk of lymph node metastasis, LVSI has not yet been identified as a predictive factor in endometrioid endometrial cancers that are limited to the uterus [7, 8].

The characteristics of lymphatic drainage differ between the lower and the upper segments of the uterine corpus [9].
This suggests that, in the case of endometrial cancer, the location of the tumour in the uterus might be a factor that may affect the correlation between the LVSI and lymph node metastasis. This is the first study to investigate the correlation of LUSI and LVSI with lymph node involvement.

\section{Objectives}

The aim of this study was to determine the effect of tumour location on the correlation between LVSI and lymph node metastasis in endometrioid endometrial cancer patients undergoing staging surgery.

\section{MATERIAL AND METHODS}

The hospital records of 376 patients undergoing staging surgery for the diagnosis of endometrial cancer between 1 January 2010 and 31 January 2019 were reviewed in this retrospective study. Ethics committee approval was obtained from our institution before the study started (11/2019). 
The study included patients whose final pathology was representative of pure endometrioid endometrial cancer and who had the information about tumour size, LVSI, and lower uterine segment involvement (LUSI) in their pathology report. Patients with non-endometrioid endometrial cancer, a mixed type histology ( $\geq 10$ non-endometrioid component), simultaneous malignancies, and with non-uterine metastasis in the intraoperative observational or frozen section examination were excluded from the study. Cases with less than 11 pelvic lymph nodes and less than 3 para-aortic lymph nodes in the pathology report, defined as an insufficient number of lymph nodes in the literature [10, 11], were not included in the study (Fig. 1).

Demographic data and the presence of diabetes proven by laboratory data (fasting plasma glucose of $\geq 126$ or 2nd-hour plasma glucose of $\geq 200$ after 75 mg of oral glucose) were obtained by reviewing the patient files [12]. Histologic type [13] and grade, [14] tumour size ( $\leq 2 \mathrm{~cm}$ or $>2 \mathrm{~cm})$, myometrial invasion percentage $(<50 \%$ or $\geq 50 \%)$, [15] LUSI (present or absent), and LVSI (present or absent) findings defined by the World Health Organization (WHO) and the International Federation of Gynecology and Obstetrics (FIGO) criteria, number of lymph nodes removed and metastasis findings, peritoneal cytology finding (benign or malign), and adenomyosis finding were obtained by reviewing the pathology reports. The stage of the disease was determined according to the FIGO 2009 criteria [16]. Cancer antigen (CA)-125 levels determined by the Roche E170 Modular System chemiluminescence method were grouped according to the cut-off value $(<17.03 \mathrm{U} / \mathrm{mL})$, which was chosen based on the laboratory reference value $(<35 \mathrm{U} / \mathrm{mL})$ and the CA-125 mean value [17]. The LUSI and LVSI statuses of the cases along with patient age, lymph node metastatic involvement, tumour size, histological grade, CA-125 levels, presence of diabetes, and adenomyosis were compared.

LVSI was defined as the accumulation of tumour cells in the nearby lymphatic and blood vessels outside of the invasive margin [2]. LUSI was defined as the presence of tumour invasion in the lower quadrant of the uterine corpus [18].

The data were expressed as mean \pm standard deviation or number and percentage. The Chi-square and Fisher's exact test were used to compare the categorical data, while the One-Way ANOVA test was used for comparisons of more than two independent variables. If normally distributed, the non-categorical data were compared using the Student's t-test; if not, they were compared using the Mann-Whitney U test. All calculations were performed using SPSS (IBM Corp. Armonk, NY, USA) version 20.0 statistical software. A p value of $<0.05$ was considered statistically significant.

\section{RESULTS}

The mean age of the 253 patients included in the study was $60.3 \pm 9.8$ years. The distribution of the number and mean age of the patients by LVSI, LUSI, and lymph node status is given in Table1. From the total cases, 42 (16.6\%) had LVSI and 49 (19.4\%) had LUSI. The distribution of the patients included in the study according to their LUSI and LVSI status is given in Table 2. A total of 19 (7.5\%) patients had malignant metastases in the lymph nodes. The distribution of lymph node metastases of patients according to

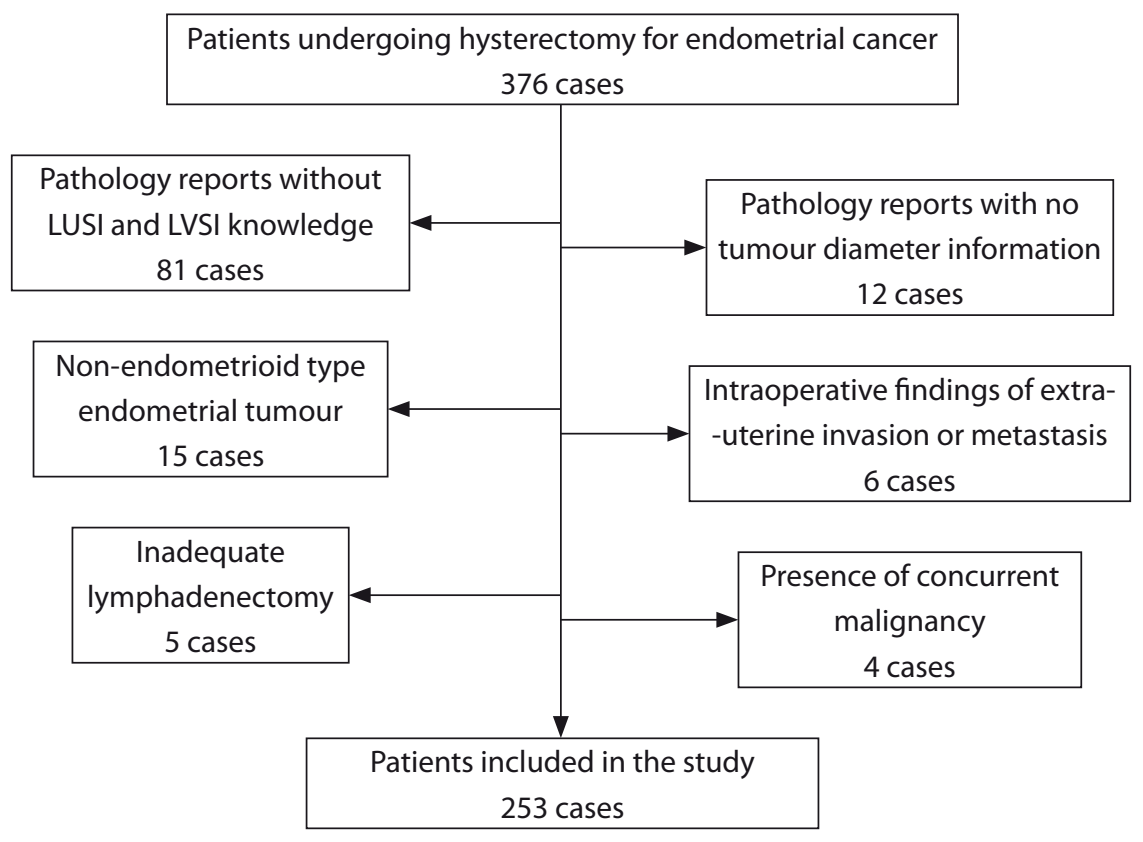

Figure 1. Flow chart of exclusion criteria 
Table 1. Number and age distribution of cases according to LVSI, LUSI, and lymph node status

\begin{tabular}{|c|c|c|c|c|c|c|c|c|c|c|c|c|}
\hline \multirow[b]{3}{*}{$n(\%)$} & \multicolumn{4}{|l|}{ LVSI } & \multicolumn{4}{|l|}{ LUSI } & \multicolumn{4}{|c|}{ Lymph node } \\
\hline & Present & Absent & \multirow{2}{*}{$P$ value } & \multirow{2}{*}{ T value } & Present & Absent & \multirow{2}{*}{$P$ value } & \multirow{2}{*}{ T value } & Malign & Benign & \multirow{2}{*}{$P$ value } & \multirow{2}{*}{ T value } \\
\hline & $42(16.6)$ & $211(83.4)$ & & & 49 (19.4) & $20480.6)$ & & & $19(7.5)$ & 234 (92.5) & & \\
\hline $\begin{array}{l}\text { Age } \\
\text { mean } \pm S D\end{array}$ & $64.1 \pm 8.7$ & $59.6 \pm 9.8$ & 0.005 & -2.818 & $63.7 \pm 10.3$ & $59.5 \pm 9.5$ & 0.007 & -2.730 & $67.2 \pm 9.5$ & $59.8 \pm 9.6$ & 0.001 & -3.261 \\
\hline
\end{tabular}

LVSI - lymphovascular space invasion; LUSI — indicating lower uterine segment involvement; $\mathrm{n}$ - number; SD — standard deviation

Table 2. Case distribution according to LUSI and LVSI conditions

\begin{tabular}{|l|l|l|l|}
\hline \multicolumn{2}{|l|}{ LUSI present $\mathbf{n}(\%)$} & LUSI absent $\mathbf{n}(\%)$ & P value \\
\hline LVSI present & LVSI absent & LVSI present & LVSI absent \\
\hline $18(36.7)$ & $31(63.3)$ & $24(11.8)$ & $180(88.2)$ \\
\hline
\end{tabular}

*Pearson chi-square

LVSI — lymphovascular space invasion; LUSI — indicating lower uterine segment involvement; $\mathrm{n}$ - number

Table 3. Distribution of lymph node metastasis cases according to LUSI and LVSI status

\begin{tabular}{|l|l|l|l|l|l|l|}
\hline $\begin{array}{l}\text { Lymph nodes } \\
\mathbf{n}(\%)\end{array}$ & \multicolumn{2}{l|}{ LVSI $\mathbf{n}(\%)$} & \multirow{2}{*}{ P value } & LUSI $\mathbf{n}(\%)$ & P value \\
\cline { 2 - 5 } & Present & Absent & Present & Absent & \\
\hline $\begin{array}{l}\text { Malignant } \\
19(7.5)\end{array}$ & $17(40.5)$ & $2(0.9)$ & $9(18.4)$ & $10(4.9)$ & $<0.05^{*}$ \\
\hline $\begin{array}{l}\text { Benign } \\
234(92.5)\end{array}$ & $25(59.5)$ & $209(99.1)$ & $<0.05^{*}$ & $40(81.6)$ & $194(95.1)$ & \\
\hline
\end{tabular}

*Fisher's exact test

LVSI — lymphovascular space invasion; LUSI — indicating lower uterine segment involvement; $\mathrm{n}$ - number

Table 4. LVSI and lymph node metastasis in LUSI-positive patients

\begin{tabular}{|c|c|c|c|c|}
\hline \multirow{2}{*}{\multicolumn{2}{|c|}{$\begin{array}{l}\text { LVSI } \\
\text { n (\%) } \\
\text { Present }\end{array}$}} & \multicolumn{2}{|c|}{$\begin{array}{l}\text { Lymph nodes } \\
\text { metastasis n (\%) }\end{array}$} & \multirow{2}{*}{$P$ value } \\
\hline & & \multirow{2}{*}{$\begin{array}{l}\text { Absent } \\
9(50.0)\end{array}$} & \multirow[b]{2}{*}{$9(50.0)$} & \\
\hline Present & $18(36.7)$ & & & \multirow[b]{2}{*}{$<0.05^{*}$} \\
\hline Absent & $31(63.3)$ & $0(0)$ & $31(100)$ & \\
\hline
\end{tabular}

*Fisher's exact test

LVSI — lymphovascular space invasion; LUSI — indicating lower uterine segment involvement; $\mathrm{n}$ - number

their LVSI and LUSI status is given in Table 3. Among the LUSI-positive cases, none of the 31 LVSI-negative cases had metastatic lymph node involvement; however, half of the 18 LVSI-positive cases had metastatic lymph node involvement. This difference was significant $(p<0.05)$. There was no significant correlation between the LUSI status and lymph node metastasis in LVSI-positive cases ( $p>0.05$ ). Lymph node metastases distribution of LUSI-positive patients by LVSI status is given in Table 4, and the distribution of lymph node metastases of LVSI-positive cases by LUSI status is given in Table 5. Abdominal irrigation cytology was reported as malignant in only 7 (2.8\%) patients. Of the patients with malignant abdominal irrigation cytology, one had LVSI only, three had both LUSI and LVSI, and the remaining patients had neither LUSI nor LVSI. A preoperative CA-125 value was
Table 5. LUSI and lymph node metastasis in LVSI-positive patients

\begin{tabular}{|c|c|c|c|c|}
\hline \multirow{2}{*}{\multicolumn{2}{|c|}{$\begin{array}{l}\text { LUSI } \\
\text { n (\%) } \\
\text { Present }\end{array}$}} & \multicolumn{2}{|c|}{$\begin{array}{l}\text { Lymph nodes } \\
\text { metastasis } \mathrm{n}(\%)\end{array}$} & \multirow{2}{*}{$P$ value } \\
\hline & & \multirow{2}{*}{$\begin{array}{l}\text { Absent } \\
9(50.0)\end{array}$} & \multirow[b]{2}{*}{$9(50.0)$} & \\
\hline Present & $18(42.9)$ & & & \multirow[b]{2}{*}{$>0.05^{*}$} \\
\hline Absent & $24(57.1)$ & $8(33.3)$ & $16(66.7)$ & \\
\hline
\end{tabular}

${ }^{*}$ Pearson chi-square

LVSI — lymphovascular space invasion; LUSI — indicating lower uterine segment involvement; $\mathrm{n}$ - number

present only in 150 (59.3\%) of patients included in the study. In order to approach the mean value of Ca-125 $(22.50 \mathrm{U} / \mathrm{mL})$ to $5 \%$ trimmed mean value $(16.32 \mathrm{U} / \mathrm{mL}), 4$ cases with CA125 above $130 \mathrm{U} / \mathrm{mL}$ were removed, then the calculation was performed and the mean value was found $17.03 \pm 15.02$. The comparison of the LVSI and LUSI status with the clinical and pathological data is presented in Table 6 .

\section{DISCUSSION}

Our study is the first to investigate the correlation of LUSI and LVSI with lymph node involvement and the factors affecting this correlation in patients with endometrioid endometrial carcinoma. The most interesting finding in our study was that of the LUSI-positive cases, none of the 31 LVSI-negative cases had metastatic lymph node involve- 


\begin{tabular}{|c|c|c|c|c|c|c|c|}
\hline \multirow{2}{*}{\multicolumn{2}{|c|}{$\begin{array}{l}\text { Investigated factors } \\
\mathrm{n}(\%) \\
\text { Absent }\end{array}$}} & \multicolumn{2}{|l|}{$\begin{array}{l}\text { LVSI } \\
\text { n (\%) }\end{array}$} & \multirow{2}{*}{$\begin{array}{l}\text { P value } \\
\text { Absent }\end{array}$} & \multicolumn{2}{|l|}{$\begin{array}{l}\text { LUSI } \\
\text { n (\%) }\end{array}$} & \multirow{2}{*}{$P$ value } \\
\hline & & Present & & & Present & & \\
\hline \multirow[b]{2}{*}{ Diabetes Mellitus } & $\begin{array}{l}\text { Absent } \\
104(41.1)\end{array}$ & 91 (87.5) & $13(12.5)$ & \multirow[b]{2}{*}{$0.143^{*}$} & $83(79.8)$ & $21(20.2)$ & \multirow[b]{2}{*}{$0.782^{*}$} \\
\hline & $\begin{array}{l}\text { Present } \\
149(58.9)\end{array}$ & $120(80.5)$ & $29(19.5)$ & & $121(81.2)$ & $28(18.8)$ & \\
\hline \multirow[b]{2}{*}{ Adenomyosis } & $\begin{array}{l}\text { Absent } \\
213(84.2)\end{array}$ & $176(82.6)$ & $37(17.4)$ & \multirow[b]{2}{*}{$0.447^{*}$} & 169 (79.3) & $44(20.7)$ & \multirow[b]{2}{*}{$0.231^{*}$} \\
\hline & $\begin{array}{l}\text { Present } \\
40(15.8)\end{array}$ & 35 (87.5) & $5(12.5)$ & & $35(87.5)$ & $5(12.5)$ & \\
\hline \multirow[b]{2}{*}{ Tumour diameter } & $\begin{array}{l}\leq 2 \mathrm{~cm} \\
107(42.3)\end{array}$ & $102(95.3)$ & $5(4.7)$ & \multirow[b]{2}{*}{$<0.05^{*}$} & $100(93.5)$ & $7(6.5)$ & \multirow[b]{2}{*}{$<0.05^{*}$} \\
\hline & $\begin{array}{l}>2 \mathrm{~cm} \\
146(57.7)\end{array}$ & 109 (74.7) & $37(25.3)$ & & $104(71.2)$ & $42(28.8)$ & \\
\hline \multirow{4}{*}{$\begin{array}{l}\text { Ca-125 } \\
\mathrm{U} / \mathrm{mL}\end{array}$} & $\begin{array}{l}<20 \\
109(72.7)\end{array}$ & $96(88.1)$ & $13(11.9)$ & \multirow[b]{2}{*}{$0.002^{*}$} & $96(88.1)$ & $13(11.9)$ & \multirow[b]{2}{*}{$0.001^{*}$} \\
\hline & $\begin{array}{l}>20 \\
41(27.3)\end{array}$ & $27(65.9)$ & $14(34.1)$ & & $26(63.4)$ & $15(36.6)$ & \\
\hline & $\begin{array}{l}<35 \\
132(88.0)\end{array}$ & 114 (86.4) & 18 (13.6) & \multirow[b]{2}{*}{$0.001^{t}$} & 113 (85.6) & 19 (14.4) & \multirow[b]{2}{*}{$0.001^{1}$} \\
\hline & $\begin{array}{l}>35 \\
18(12.0)\end{array}$ & $19(50.0)$ & $9(50.0)$ & & $9(50.0)$ & $9(50.0)$ & \\
\hline \multirow{3}{*}{ Histologic grade } & $\begin{array}{l}1 \\
147(58.1)\end{array}$ & 141 (95.9) & $6(4.1)$ & \multirow{3}{*}{$<0.05^{\prime}$} & $127(86.4)$ & $20(13.6)$ & \multirow{3}{*}{$0.013^{v}$} \\
\hline & $\begin{array}{l}2 \\
90(35.6)\end{array}$ & $62(68.9)$ & $28(31.1)$ & & $67(74.4)$ & $23(25.6)$ & \\
\hline & $\begin{array}{l}3 \\
16(6.3)\end{array}$ & $8(50.0)$ & $8(50.0)$ & & $10(62.5)$ & $6(37.5)$ & \\
\hline \multirow[b]{2}{*}{$\mathrm{Ml}$} & $\begin{array}{l}<50 \% \\
165(65.2)\end{array}$ & $158(95.8)$ & $7(4.2)$ & \multirow[b]{2}{*}{$<0.05^{*}$} & $150(90.9)$ & $15(9.1)$ & \multirow[b]{2}{*}{$<0.05^{*}$} \\
\hline & $\begin{array}{l}\geq 50 \% \\
88(34.8)\end{array}$ & $53(60.2)$ & $35(39.8)$ & & $54(61.4)$ & $34(38.6)$ & \\
\hline \multirow{4}{*}{ Stage } & $\begin{array}{l}\text { IA } \\
165(65.2)\end{array}$ & $\begin{array}{l}150 \\
(90.9)\end{array}$ & $\begin{array}{l}15 \\
(9.1)\end{array}$ & \multirow{4}{*}{$<0.05^{\mathrm{r}}$} & $\begin{array}{l}158 \\
(95.8)\end{array}$ & $\begin{array}{l}7 \\
(4.2)\end{array}$ & \multirow{4}{*}{$<0.05^{x}$} \\
\hline & $\begin{array}{l}\text { IB } \\
59(23.3)\end{array}$ & $\begin{array}{l}44 \\
(74.6)\end{array}$ & $\begin{array}{l}15 \\
(25.4)\end{array}$ & & $\begin{array}{l}43 \\
(72.9)\end{array}$ & $\begin{array}{l}16 \\
(27.1)\end{array}$ & \\
\hline & $\begin{array}{l}\text { II } \\
10(4.0)\end{array}$ & $\begin{array}{l}0 \\
(0)\end{array}$ & $\begin{array}{l}10 \\
(100)\end{array}$ & & $\begin{array}{l}8 \\
(80.0)\end{array}$ & $\begin{array}{l}2 \\
(20.0)\end{array}$ & \\
\hline & $\begin{array}{l}\text { IIIC } \\
19(7.5)\end{array}$ & $\begin{array}{l}10 \\
(52.6)\end{array}$ & $\begin{array}{l}9 \\
(47.4)\end{array}$ & & $\begin{array}{l}2 \\
(10.5)\end{array}$ & $\begin{array}{l}17 \\
(89.5)\end{array}$ & \\
\hline
\end{tabular}

*Pearson chi-square, ${ }^{\text {}}$ Fisher's exact test, 'One-Way ANOVA

LVSI — lymphovascular space invasion; LUSI — indicating lower uterine segment involvement; $\mathrm{MI}$ — myometrial invasion; $\mathrm{n}$ — number

ment. However, half of the 18 LVSI-positive cases did have metastatic lymph node involvement $(p<0.05)$.

There is very little literature on the correlation between LUSI and LVSI. Only Erkaya et al. have investigated the effects of LUSI on survival in endometrial cancer. They examined the effects of LUSI and LVSI as comorbidities on lymph node metastasis and reported that the tumours may have different clinicopathological characteristics due to the differences in lymphatic drainage between the lower and upper segments of the uterus in LUSI-positive patients [19].
Gemer et al. (2009) [20] reported a significant correlation between LUSI and LVSI. In a study by Miyoshi et al. (2018) [21] investigating the prognostic characteristics of lower uterine segment tumors, it was observed that though not significantly, LVSI was more common in the primary tumours of the lower uterine segment. The correlation between the location of the primary tumour and lymph node metastasis was found as significant in the same study. Both positive LUSI and LVSI were significantly associated with lymph node metastasis in our study as well. 
The correlation between LVSI and pelvic and para-aortic lymph node involvement in endometrial cancer has been known for a long time [22-24]. However, LVSI is not a direct influence in lymphadenectomy and adjuvant therapy due to a different interpretation of the pathologist and a lack of diagnostic standardization $[2,8]$. Furthermore, many pathologists do not focus on LVSI in frozen section examinations as much as they focus on the grade, tumour size, and myometrial invasion. In the study by Vaizoglu et al. (2013) [6] investigating the predictive importance of LVSI in terms of lymph node metastasis in early stage endometrial cancer patients, it was found that LVSI was the only predictive factor for lymph node metastasis, suggesting that pathologists should focus on LVSI in the frozen examination. The compliance rate for LVSI was found to be moderate with $68.3 \%$ in a study evaluating the final pathology and frozen section compliance in early stage endometrial cancer cases [25]. The significant correlation between LVSI and lymph node metastasis in LUSI patients suggests that pathologists should also focus on LVSI findings regarding the decision to undergo lymphadenectomy, especially in frozen examinations of cases with endometrial cancer limited to the uterus and lower uterine segment involvement in our study.

The CA-125 values of the patients in our study were significantly higher in both LUSI- and LVSI-positive cases than in the LUSI- and LVSI-negative ones. Although the correlation of endometrial cancer with CA-125 elevation has been known for a long time, [26] we could not find any study evaluating CA-125 level in relation to LVSI and lymph node involvement. One study found no significant correlation between LUSI positivity and CA-125 levels. We found no additional studies on this topic.

In our study, there was no significant correlation between diabetes and neither LVSI nor LUSI. To the best of our knowledge, there is only one study investigating the correlation between LVSI positivity and diabetes in endometrial cancer cases, which found no significant correlation between diabetes and LVSI [27]. We did not find any study directly investigating the correlation between LUSI and diabetes, but we found that there was no significant correlation in an article investigating the correlation between body mass index and LUSI [28].

In the literature, none of the articles investigating the LUSI or LVSI status in endometrioid endometrial carcinoma cases discussed adenomyosis finding. The reason for investigating adenomyosis in our study is that there are studies suggesting that the coexistence of adenomyosis and endometrioid endometrial cancer may affect the LVSI status [29, 30]. Neither LUSI nor LVSI was significantly correlated with adenomyosis coexistence in our study.

The mean age was significantly higher in both the LUSI-positive group and the LVSI-positive group than the patients without involvement in our study. Most of the studies in the literature did not find any significant correlation between age and LUSI [19, 20, 31, 32]. Considering the correlation between patient age and LVSI status, it is seen that there are publications which found both significant [3, 33] and insignificant [27] correlations.

Significant correlations have been reported between tumour size, [34, 19] histological grade [19, 33], and myometrial invasion [19, 20, 33]. These, along with the LUSI and LVSI statuses of patients, affect the decision to proceed with intraoperative lymphadenectomy in endometrial cancer surgery. Furthermore, these correlations were also present in our study.

The limitation of this study is the lack of sufficient information on tumour size, LUSI, and LVSI in some pathology reports, especially between 2010 and 2011. To ensure the exclusion of fewer cases in future studies, a correlation should be established between gynaecological oncologists and pathologists, particularly with regard to the content of the pathology report.

Although a retrospective design was used in this study, we believe that this was compensated for by the fact that 1) the operations were performed by experienced gynaecological oncologists in a single institution, 2) an adequate number of lymph nodes were obtained from all patients undergoing staging surgery, and 3 ) the operation materials were evaluated by the same gynaecological pathology team.

\section{CONCLUSIONS}

We believe that, regarding lymph node metastasis in endometrioid endometrial cancer, LUSI positivity signals the necessity to focus on LVSI. Therefore, in such cases, surgeons should ask for LUSI and LVSI findings from pathologists, in order to facilitate decisions regarding staging surgery.

\section{Acknowledgements}

We would like to thank Editage (www.editage.com) for English language editing. We thank Betul Cokmez, MD for comments that greatly improved the manuscript.

\section{REFERENCES}

1. Bray F, Ferlay J, Soerjomataram I, et al. Global cancer statistics 2018 GLOBOCAN estimates of incidence and mortality worldwide for 36 cancers in 185 countries. CA Cancer J Clin. 2018; 68(6): 394-424, doi: 10.3322/caac.21492, indexed in Pubmed: 30207593.

2. Bosse T, Peters EEM, Creutzberg $\mathrm{CL}$, et al. Substantial lymph-vascular space invasion (LVSI) is a significant risk factor for recurrence in endometrial cancer--A pooled analysis of PORTEC 1 and 2 trials. Eur J Cancer. 2015; 51(13): 1742-1750, doi: 10.1016/j.ejca.2015.05.015, indexed in Pubmed: 26049688.

3. Jorge S, Hou JY, Tergas Al, et al. Magnitude of risk for nodal metastasis associated with lymphvascular space invasion for endometrial cancer. Gynecol Oncol. 2016; 140(3):387-393, doi: 10.1016/j.ygyno.2016.01.002, indexed in Pubmed: 26768835.

4. Bendifallah S, Canlorbe G, Raimond E, et al. A clue towards improving the European Society of Medical Oncology risk group classification in apparent early stage endometrial cancer? Impact of lymphovascular space invasion. Br J Cancer. 2014; 110(11): 2640-2646, doi: 10.1038/bjc.2014.237, indexed in Pubmed: 24809776. 
5. Sadozye AH, Harrand RL, Reed NS. Lymphovascular Space Invasion as a Risk Factor in Early Endometrial Cancer. Curr Oncol Rep. 2016; 18(4): 24, doi: 10.1007/s11912-016-0505-1, indexed in Pubmed: 26922330.

6. Vaizoglu F, Yuce K, Salman MC, et al. Lymphovascular space involvement is the sole independent predictor of lymph node metastasis in clinical early stage endometrial cancer. Arch Gynecol Obstet. 2013; 288(6): 1391-1397, doi: 10.1007/s00404-013-2913-x, indexed in Pubmed: 23764931

7. Taşkın S, Şükür YE, Varlı B, et al. Nomogram with potential clinical use to predict lymph node metastasis in endometrial cancer patients diagnosed incidentally by postoperative pathological assessment. Arch Gynecol Obstet. 2017; 296(4): 803-809, doi: 10.1007/s00404-017-4477-7, indexed in Pubmed: 28762064

8. Sahin H, Meydanli MM, Sari ME, et al. Recurrence patterns and prognostic factors in lymphovascular space invasion-positive endometrioid endometrial cancer surgically confined to the uterus. Taiwan J Obstet Gynecol. 2019; 58(1): 82-89, doi: 10.1016/j.tjog.2018.11.016, indexed in Pubmed: 30638487.

9. Geppert B, Lönnerfors C, Bollino M, et al. A study on uterine lymphatic anatomy for standardization of pelvic sentinel lymph node detection in endometrial cancer. Gynecol Oncol. 2017; 145(2): 256-261, doi: 10.1016/j.ygyno.2017.02.018, indexed in Pubmed: 28196672.

10. Chan JK, Urban R, Cheung MK, et al. Lymphadenectomy in endometrioid uterine cancer staging: how many lymph nodes are enough? A study of 11,443 patients. Cancer. 2007; 109(12): 2454-2460, doi: 10.1002/cncr.22727, indexed in Pubmed: 17503431.

11. Mariani A, Dowdy SC, Cliby WA, et al. Prospective assessment of lymphatic dissemination in endometrial cancer: a paradigm shift in surgical staging. Gynecol Oncol. 2008; 109(1): 11-18, doi: 10.1016/j. ygyno.2008.01.023, indexed in Pubmed: 18304622.

12. Report of the Expert Committee on the Diagnosis and Classification of Diabetes Mellitus. Diabetes Care. 1997; 20(7): 1183-1197, doi: 10.2337/diacare.20.7.1183.

13. Tavassoli FA, Devilee P. Pathology and genetics. Tumors of the breast and female genital organs. WHO Classification of Tumors. In: Silverberg SG, Kurman RJ, Nogales F, Mutter GL, Kubik-Huch RA, (eds). Epithelial tumors and related lesions. Tumors of the Uterine Corpus. Lyon: IARC Press. ; 2003: 221-228.

14. Creasman WT, Odicino F, Maisonneuve P, et al. Carcinoma of the corpus uteri. FIGO 26th Annual Report on the Results of Treatment in Gynecological Cancer. Int J Gynaecol Obstet. 2006; 95 Suppl 1: S105-S143, doi: 10.1016/S0020-7292(06)60031-3, indexed in Pubmed: 17161155.

15. Mariani A, Dowdy SC, Cliby WA et al. Prospective assessment of lymphatic dissemination in endometrial cancer: a paradigm shift in surgical staging. Gynecol Oncol. 2008; 109(1): 11-18, doi: 10.1016/j. ygyno.2008.01.023, indexed in Pubmed: 18304622.

16. Pecorelli S. Revised FIGO staging for carcinoma of the vulva, cervix, and endometrium. Int J Gynaecol Obstet. 2009; 105(2): 103-104, indexed in Pubmed: 19367689.

17. Nithin KU, Sridhar MG, Srilatha K, et al. CA 125 is a better marker to differentiate endometrial cancer and abnormal uterine bleeding. Afr Health Sci. 2018; 18(4): 972-978, doi: 10.4314/ahs.v18i4.17, indexed in Pubmed: 30766562.

18. Hachisuga T, Kaku T, Enjoji M. Carcinoma of the Lower Uterine Segment. Clinicopathologic Analysis of 12 Cases. International Journal of Gynecological Pathology. 1989; 8(1): 26-35, doi: 10.1097/00004347198903000-00004.

19. Erkaya $\mathrm{S}$, Öz M, Topçu HO, et al. Is lower uterine segment involvement a prognostic factor in endometrial cancer? Turk J Med Sci. 2017; 47(1): 300-306, doi: 10.3906/sag-1602-137, indexed in Pubmed: 28263506.
20. Gemer O, Gdalevich M, Voldarsky M, et al. Lower uterine segment involvement is associated with adverse outcome in patients with stage I endometroid endometrial cancer: results of a multicenter study. Eur J Surg Oncol. 2009; 35(8): 865-869, doi: 10.1016/j.ejso.2008.10.007, indexed in Pubmed: 19013746.

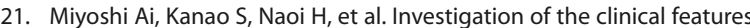
of lower uterine segment carcinoma: association with advanced stage disease and indication of poorer prognosis. Arch Gynecol Obstet. 2018; 297(1): 193-198, doi: 10.1007/s00404-017-4576-5, indexed in Pubmed: 29116461.

22. Koskas M, Bassot K, Graesslin O, et al. Impact of lymphovascular space invasion on a nomogram for predicting lymph node metastasis in endometrial cancer. Gynecol Oncol. 2013; 129(2): 292-297, doi: 10.1016/j. ygyno.2013.02.027, indexed in Pubmed: 23480871.

23. Sarı ME, Meydanlı MM, Yalçın I, et al. Risk Factors for Lymph Node Metastasis among Lymphovascular Space Invasion-Positive Women with Endometrioid Endometrial Cancer Clinically Confined to the Uterus. Oncol Res Treat. 2018; 41(12): 750-754, doi: 10.1159/000492585, indexed in Pubmed: 30419557.

24. Sari ME, Yalcin I, Sahin $\mathrm{H}$, et al. Risk factors for paraaortic lymph node metastasis in endometrial cancer. Int J Clin Oncol. 2017; 22(5): 937-944, doi: 10.1007/s10147-017-1139-5, indexed in Pubmed: 28523533.

25. Kumar S, Bandyopadhyay S, Semaan A, et al. The role of frozen section in surgical staging of low risk endometrial cancer. PLoS One. 2011; 6(9): e21912, doi: 10.1371/journal.pone.0021912, indexed in Pubmed: 21912633.

26. Yasa C, Takmaz O, Dural O, et al. The Value of Tumor Markers in Endometrial Carcinoma: Review of Literature. J Cancer Ther. 2013; 04(05): 966-970, doi: 10.4236/jct.2013.45110.

27. Neal SA, Graybill WS, Garrett-Mayer E, et al. Lymphovascular space invasion in uterine corpus cancer: What is its prognostic significance in the absence of lymph node metastases? Gynecol Oncol. 2016; 142(2): 278282, doi: 10.1016/j.ygyno.2016.05.037, indexed in Pubmed: 27261326.

28. Westin SN, Lacour RA, Urbauer DL, et al Carcinoma of the lower uterine segment: a newly described association with Lynch syndrome. J Clin Oncol. 2008; 26(36): 5965-5971, doi: 10.1200/JCO.2008.18.6296, indexed in Pubmed: 19001318.

29. Ismiil N, Rasty G, Ghorab Z, et al. Adenomyosis involved by endometria adenocarcinoma is a significant risk factor for deep myometrial invasion. Ann Diagn Pathol. 2007; 11(4): 252-257, doi: 10.1016/j.anndiagpath.2006.08.011, indexed in Pubmed: 17630108.

30. Gizzo S, Patrelli TS, Dall'asta A, et al. Coexistence of adenomyosis and endometrioid endometrial cancer: Role in surgical guidance and prognosis estimation. Oncol Lett. 2016; 11(2): 1213-1219, doi: 10.3892/ol.2015.4032, indexed in Pubmed: 26893721.

31. Kizer NT, Gao F, Guntupalli S, et al. Lower uterine segment involvement is associated with poor outcomes in early-stage endometrioid endometrial carcinoma. Ann Surg Oncol. 2011; 18(5): 1419-1424, doi: 10.1245/s10434-010-1454-9, indexed in Pubmed: 21181281.

32. Lavie O, Uriev L, Gdalevich M, et al. The outcome of patients with stage I endometrial cancer involving the lower uterine segment. Int J Gynecol Cancer. 2008; 18(5): 1079-1083, doi: 10.1111/j.1525-1438.2007.01150.x, indexed in Pubmed: 18081795.

33. Hahn HS, Lee IH, Kim TJ, et al. Lymphovascular space invasion is highly associated with lymph node metastasis and recurrence in endometrial cancer. Aust N Z J Obstet Gynaecol. 2013; 53(3): 293-297, doi: 10.1111/ajo.12089, indexed in Pubmed: 23600915.

34. Laufer J, Scasso S, Papadia A, et al. Association between tumor diameter and lymphovascular space invasion among women with early-stage endometrial cancer. Int J Gynaecol Obstet. 2013; 123(2): 142-145, doi: 10.1016/j.ijgo.2013.05.012, indexed in Pubmed: 23954391. 